\title{
Território, Territorialidade e Identidade Territorial: categorias para análise da dinâmica territorial quilombola no cenário geográfico
}

\author{
Territory, Territoriality and Territorial Identity: categories for analysis of the \\ dynamics territorial quilombola in geographic scenery
}

\begin{abstract}
Andressa Rodrigues Sensato Oliveira Graduação em História pela Universidade Estadual do Norte do Paraná - UENP, Graduação em Geografia pela UENP, Mestranda em Geografia pela Universidade Estadual de Londrina - UEL andressarso90@gmail.com
\end{abstract}

Carla Holanda da Silva

Graduação em Geografia pela Universidade Estadual de Londrina - UEL, Mestrado em Geografia pela Universidade Federal do Paraná - UFPR, Doutorado em Geografia pela UFPR, Docente do Curso de Geografia da Universidade Estadual do Norte do Paraná - UENP carlaholanda@uenp.edu.br

\begin{abstract}
Resumo
As Comunidades Quilombolas, pós-abolição da escravatura em 1888, permaneceram silenciadas e esquecidas pela sociedade e, mesmo pela ciência geográfica, resultado da dinâmica estabelecida no período escravista, carregada de estereótipos acerca dos afrodescendentes. E assim, mesmo após a Constituição Federal de 1988, que criou a primeira legislação que atendia as demandas quilombolas, e trouxe a tona esses sujeitos, os debates a seu respeito ainda são ínfimos. Diante deste cenário, com o intuito de suprir esta carência de estudos, especialmente na ciência geográfica, o presente artigo tem como objetivo central discutir os conceitos de território, territorialidade e identidade territorial, entrelaçado a realidade das comunidades quilombolas. Para este propósito, foram utilizados de arcabouço teórico com autores que discutem a questão quilombola, identidade, território e identidade territorial. Além da análise da legislação brasileira que versa sobre a temática quilombola. Ao longo da reflexão verificou-se que, na compreensão da dinâmica territorial quilombola, estes conceitos geográficos destacam-se e alicerçam as relações estabelecidas por essas comunidades com seu próprio núcleo e/ou com o entorno e poder público.
\end{abstract}

Palavras-chave: Comunidades quilombolas, Território, Territorialidades, Identidade territorial.

\begin{abstract}
The Quilombo Communities, after the abolition of slavery in 1888, remained silenced and forgotten by society and even the geographical science, the result of the established dynamics in the slave period, full of stereotypes about people of African descent. And so, even after the Federal Constitution of 1988, which created the first legislation that met the demands Maroons, and brought up these subjects, discussions about them are still negligible. In this scenario, in order to address this lack of studies, especially in geographical science, this article is mainly aimed to discuss the concepts of territory, territoriality and territorial identity, intertwined reality of quilombo communities. For this purpose, we used the theoretical framework with authors who discuss the quilombola question, identity, territory and territorial identity. In addition to the analysis of Brazilian legislation that deals with the quilombola theme. Along the reflection was found, in understanding of the quilombo territorial dynamics, that, these geographical concepts stand out and underpin the relations established by these communities with their own core and / or the environment and public authorities.
\end{abstract}

Keywords: Quilombo Communities, Territory, Territoriality, Territorial identity. 


\section{INTRODUÇÃO}

As comunidades quilombolas, após abolição da escravidão em 1888, continuaram marginalizadas pelo poder público e pela sociedade brasileira, resquício da mentalidade e dos estereótipos criados pelo sistema escravista, que considerava o negro inferior.

Unindo-se a essa visão, para as comunidades quilombolas, a realidade mostrava-se mais desfavorável ainda, posto que a imagem que se tinha dos quilombolas estava atrelada a uma visão histórica de quilombo que, destacava-os como rebeldes, violentos, transgressores e inferiores (SILVA, 2013). E, consequentemente não havia nenhum interesse em sua reintegração social.

Neste contexto, acreditava-se que as comunidades quilombolas haviam se extinguido junto com o próprio sistema escravocrata (LÖWEN SAHR; ALVES, 2011). E assim, o poder público só trouxe a tona discussões a respeito desses grupos a partir da Constituição Federal de 1988. Entretanto, neste primeiro momento ainda de forma bem superficial.

Assim, em função deste contexto de invisibilidade, é possível verificar que atualmente, mesmo na Ciência Geográfica, este debate ainda possui pouca expressão, quando comparada a outras áreas do conhecimento, como Antropologia, Sociologia e História. Contudo, entende-se que os estudos geográficos são fundamentais para compreender a dinâmica territorial quilombola, pois são configurações relevantes, dada a contribuição dos afrodescendentes para a formação socioespacial do Brasil.

Nesse contexto, a fim de suprir tal carência, o presente artigo tem por objetivo discutir os conceitos de território, territorialidades e identidade territorial a partir da realidade quilombola, pois entende-se que estes conceitos são primordiais para sua compreensão.

Para tanto, o presente estudo envolveu a análise de referenciais teóricos de autores da Geografia e de outras ciências como História, Antropologia, Sociologia, que discutem a temática quilombola, território, identidade e identidade territorial. Dentre eles, Arruti (2006), Haesbaert (1999, 2004, 2006), Raffestin (1993), entre outros. E análise das legislações federais, acerca da temática quilombola a partir de 1988, responsáveis por identificar e certificar as comunidades quilombolas, e regulamentar seu território. A fim de verificar como estas leis influenciaram na dinâmica territorial dessas comunidades, e, portanto, na materialidade dos conceitos geográficos trabalhados neste artigo.

Deste modo, neste trabalho em um primeiro momento, discute-se os conceitos de território e territorialidades, sobretudo nas análises geográficas. Em um segundo momento, o conceito de identidade territorial entrelaçado a realidade das comunidades quilombolas. E, na sequência, apresenta-se um panorama das legislações federais acerca das comunidades quilombolas. 


\section{TERRITÓRIO, TERRITORIALIDADES: CATEGORIAS PARA ANÁLISE DA REALIDADE QUILOMBOLA}

A partir da análise de diferentes teóricos que discutem as comunidades quilombolas nacionais, como Arruti (2006) e Fiabani (2005), constatou-se que na compreensão de suas dinâmicas territoriais, seja na Geografia ou nas demais ciências, os conceitos de análise: território e territorialidades destacam-se. Portanto, no trabalho com esta temática, compreendê-los mostrou-se essencial, dado sua importância no entendimento dessa questão.

Assim, no estudo específico do conceito de território verificou-se que os debates a seu respeito, superam as análises geográficas, pois como aponta Haesbaert (2004), embora o território seja um conceito central para a Geografia, por referir-se as espacialidades humanas, é também investigado nas demais ciências.

Por exemplo, na Ciência Política o território é entendido a partir das relações de poder, relacionadas ao Estado (HAESBAERT, 2004). Na Economia, como uma fonte de recursos (HAESBAERT, 2004). Na Antropologia, destaca-se sua dimensão simbólica, no estudo, sobretudo, das sociedades tradicionais (HAESBAERT, 2004). Na Sociologia, o seu papel de interventor nas relações sociais (HAESBAERT, 2004). E, na Psicologia o seu caráter subjetivo e pessoal, em uma escala individual, refletindo a identidade do sujeito (HAESBAERT, 2004).

Além disso, as interpretações a seu respeito são diversas, mesmo na Geografia, pois varia de acordo com a corrente geográfica ou autor que o analisa, como enfatiza Haesbaert (2004, p.39), "Mas não pensemos que essa polissemia acaba quando adentramos a seara da Geografia".

Em uma síntese apresentada por Haesbaert (2004), ele aponta que existem três principais leituras sobre território na Geografia. Entre elas, a leitura política de território, que se refere à relação espaço-poder e que é uma das concepções mais aceitas na ciência em questão, poder que não necessariamente é exercido pelo Estado (HAESBAERT, 2004). Há também a leitura econômica de território, em que o mesmo é entendido como um recurso econômico (HAESBAERT, 2004). E ainda, a perspectiva cultural ou simbólica-cultural, na qual o território é visto como produto da apropriação simbólica, que um determinado grupo faz de um espaço (HAESBAERT, 2004).

$\mathrm{Na}$ Geografia, a primeira apropriação do conceito foi realizada pelo alemão Friedrich Ratzel, em seus estudos em Geografia Política, no século XIX (SILVA, 2013). Tais escritos e discussões são frutos do contexto político e intelectual, resultante do processo mal sucedido de unificação da Alemanha (COSTA, 1992).

Em suas reflexões, baseando-se nas ciências naturais, Ratzel compreendia o território a partir da perspectiva biológica, isto é, a superfície terrestre como imprescindível para o 
desenvolvimento de um Estado (COSTA, 1992). Dessa maneira, um Estado apenas se desenvolveria se o seu território tivesse as condições propícias de solo, clima, relevo, entre outros.

Além disso, inserido no contexto do período, Ratzel afirmava a necessidade de um território comum, unificado, representado por um Estado forte e centralizador que produziria políticas territoriais voltadas para a organização e desenvolvimento do território, de acordo com Costa (1992). Enfatiza assim, o caráter político do território, vinculado diretamente a relações de poder, sobretudo estatais.

Esse vínculo de abordagem a partir das relações de poder, já evidente em Ratzel, é ainda uma referência para muitos autores e para a sociedade em geral, pois de acordo com Souza (2013, p.78), “[...] o território geralmente é percebido, mesmo no âmbito do senso comum, como um espaço político $[\ldots]$ ”.

Porém, Souza (2013) salienta que a concepção política de território, deve ser apenas uma primeira aproximação com o conceito, que embora necessária, é insuficiente. Nas palavras do autor, “Toma-lá como se ela fosse, a um só tempo, o início e o fim da tarefa de conceituação, significa substituir o esforço de reflexão conceitual pela memorização de uma definição preparatória [...]" (SOUZA, 2013, p.07).

Souza (2013) afirma ainda que, embora o território seja um espaço definido e delimitado por relações de poder, não implicam apenas no poder exercido pelo uso de coerção violenta, mas também do entendimento mútuo e legitimidade por parte de quem o exerce e sobre o qual é exercido.

Tal teórico ainda destaca que, esse poder não necessariamente precisa ser exercido pelo Estado, como Ratzel afirmava, mas por qualquer grupo que tenha condições efetivas para isso (SOUZA, 2013). A exemplo das comunidades quilombolas, que embora não seja uma instituição estatal, possui no território quilombola sua principal referência e, a partir desse, manifesta variadas relações de poder.

Souza (2013) coloca também que na análise do território, não somente a dimensão política é um elemento a ser considerado, pois existem outras facetas da vida social, que interferem diretamente ou indiretamente sobre esta categorial espacial, como é caso da cultura e da economia. Para tanto, o autor afirma que:

\footnotetext{
Mais uma vez: o que "define" o território é, em primeiríssimo lugar, o poder. Ou, em outras palavras, o que determina o "perfil" do conceito é a dimensão política das relações sociais [...]. Isso não quer dizer, [...] que a cultura (o simbolismo, as teias de significados, as identidades...) ou a economia (o trabalho, os processos de produção e circulação de bens) não sejam relevantes ou não estejam contemplados [...]. (SOUZA, 2013, p.88).
}

Nesse sentido, é importante destacar a posição de Santos e Silveira (2006) que entendem o território como uma construção social, isto é, o território como uma porção do espaço, apropriado e 
utilizado das mais diversas formas pela sociedade, a partir da sua organização, em diversos contextos históricos.

Nessa mesma perspectiva, Saquet (2009), também afirma que o território é uma construção social, realizada, portanto, coletivamente e multidimensionalmente.

Portanto, pode-se afirmar que a análise do contexto histórico dos grupos quilombolas, para entendimento de sua dinâmica territorial passada e atual, é imprescindível, uma vez os elementos, que influenciam nas relações estabelecidas com esses grupos com o território, podem apresentar-se. Pois, como bem aponta Santos e Silveira (2006), a construção social do território, é marcada também pela historicidade.

Partilhando de concepções semelhantes aos dos autores supracitados Haesbaert (2006), destaca que o território é um espaço apropriado pelos grupos, não apenas politicamente, mas também economicamente e culturalmente. E também constituído por um jogo de complexas relações, entre os grupos, que ora o dominam, ora perdem esse domínio frente a outros grupos mais fortes ou melhores articulados (HAESBAERT, 2006).

Nessa mesma lógica acerca das produções territoriais, que ultrapassam as noções de poder diretamente vinculadas as questões políticas, Raffestin (1993, p. 155), coloca que o território “[...] cristaliza todo um conjunto de fatores, dos quais uns são físicos, outros humanos, econômicos [...], sociais e/ou culturais".

Para Raffestin (1993) todo território implica em uma delimitação material ou imaterial. No campo concreto, representada pelos limites físicos e definida pelos atores envolvidos e no campo abstrato por meio de representações (RAFFESTIN, 1993). Tem-se assim como exemplo, os territórios de diversas comunidades quilombolas, que anteriormente as delimitações realizadas pelos órgãos governamentais, já estavam fixados no imaginário dos respectivos grupos.

Além disso, conforme Raffestin (1993), as relações estabelecidas no território não se esgotam em seus limites físicos. Nesse sentido, a dinâmica territorial das comunidades quilombolas, é um exemplo, pois a expressão de sua territorialidade supera o seu papel no território primário. Uma vez que, os comunitários também estabelecem variadas relações com o entorno da comunidade, sejam estas amistosas ou conflituosas.

Raffestin (1993) afirma também que, os atores ao se apropriarem dos espaços acabam por “territorializar" os mesmos, sustentados por um conjunto de ações, posturas, práticas, comportamentos, enfim códigos que revelam relações de poder, fundamentais para esse processo de empoderamento e manutenção do território. Essa ação pode ser observada nas comunidades quilombolas por um conjunto de práticas e normas intrínsecas a esses grupos, que pode ser observada por meio do tripé citado por Arruti (2006), a respeito da definição de comunidade 
quilombola, alicerçado em um uso comum da terra, etnicidade e reminiscências sobre o passado escravista.

Neste cenário de encontros com "o outro", definem-se as territorialidades específicas, seja ela quilombola ou de qualquer outro grupo social. Estas são entendidas por Raffestin (1993, p. 158) como a "[...] multidimensionalidade do "vivido" territorial". Isto é, “[...] um conjunto de relações que se originam num sistema tridimensional sociedade-espaço-tempo" (RAFFESTIN, 1993, p. 160). Em síntese, são dinâmicas e resultam das diversas relações mantidas no território.

Portanto, as territorialidades não produzem apenas conflitos, mas também promovem trocas enriquecedoras, em função do fortalecimento das identidades forjadas a partir desses encontros (HAESBAERT, 2006). Tal realidade pode ser identificada nas comunidades quilombolas de modo geral, visto que embora o processo de certificação quilombola e regularização fundiária, tenha potencializado a ocorrência de conflitos, especialmente pela posse de terras, devido a interesse de outros sujeitos, a exemplo dos latifundiários, no território quilombola. Tais embates propiciam em determinados casos o fortalecimento das identidades coletivas, como um ato de resistência.

Entretanto, "Conceber a territorialidade como uma simples ligação com o espaço seria fazer renascer um determinismo sem interesse. É sempre uma relação, mesmo que diferenciada, com os outros atores" (RAFFESTIN, 1993, p. 161). Verifica-se assim, uma crítica por parte do autor as análises que por ventura situem as territorialidades apenas no campo do físico, considerando-a muito simplista, visto que as interações com outros atores, sobretudo, externamente ao território, é um elemento relevante em sua configuração.

Em síntese, atualmente, os estudos acerca do território na Geografia, abordam esta categoria espacial, pelo viés das relações de poder. Seja ele político, econômico, cultural, material ou imaterial. Nesse sentido, apresentam-se análises que ultrapassam a dimensão física e interna do território, compreendendo também, as representações e as relações com os agentes externos, entendidos como um dos principais fomentadores das territorialidades.

Essas concepções multidimensionais permitem entender as produções territoriais e territorialidades vivenciadas pelos quilombolas. Posto que, a análise das suas relações com o território são complexas e requerem uma compreensão além do espaço concreto vivenciado e das relações políticas. Pois neste caso, o território é também um espaço de socialização, de manifestação de cultura e fonte de recursos, numa perspectiva econômica. Assim, entende-se que no território tais dimensões perpassam-se.

Tais aspectos que norteiam o território e, consequentemente, os grupos que vivem nele e suas territorialidades, acabam de alguma forma influindo, em diferenciações entre os grupos. Isto é, no surgimento de identidades, que no território adquirem o status de identidades territoriais. Termo 
esse que será discutido detalhadamente a seguir a fim de proporcionar um melhor entendimento do que vem a ser a identidade quilombola, uma vez que este conceito também possui papel de destaque, junto ao conceito de território e territorialidade, nas análises acerca da questão quilombola.

\section{IDENTIDADE E IDENTIDADE TERRITORIAL: CONCEPÇÕES A LUZ DA REALIDADE QUILOMBOLA}

Em geral, os grupos que compõem a sociedade possuem identidades que podem ser intrínsecas, isto é, particulares a cada grupo, ou fruto de uma junção de características resultantes da vivência social.

Nesse sentido, verifica-se que os remanescentes quilombolas, assim como outros grupos sociais, possuem identidades próprias e as manifestam de acordo com suas especificidades, necessidades e interesses, relacionados ao contexto vivenciado. Tal realidade é possível vislumbrar via trabalhos de teóricos como Fiabani (2005) e Arruti (2006).

O termo identidade, assim como a noção de território, possui inúmeras significações, especialmente na Antropologia, Sociologia, Psicologia, Ciências Sociais, que são as principais ciências que explora este conceito, mas também na Geografia.

As discussões a respeito do conceito de identidade vêm sendo realizadas desde o final do século XVIII e, nos últimos dois séculos destacaram-se ainda mais, principalmente nas Ciências Sociais, em razão das mudanças ocorridas recentemente, em que diversos grupos como, mulheres, negros, indígenas, homossexuais, entre outros, passaram a reivindicar uma visibilidade maior na sociedade e, consequentemente uma revisão na literatura sobre a temática (ANDRÉ, 2008).

Para alguns teóricos, sobretudo da Psicologia, o termo identidade abarca o pessoal, a construção biopsicológica do indivíduo (ANDRÉ, 2008). E, para outros, o termo refere-se ao coletivo/social, relacionada à identidade social, destacando-se os aspectos socioculturais, contidos na noção de grupo social (ANDRÉ, 2008).

Esse processo de construção da identidade, realizada no âmbito individual e coletivo, faz menção ao fato de que o indivíduo vai se desenvolvendo como um ser único, com suas especificidades, ao longo de sua trajetória de vida particular (ANDRÉ, 2008). E, que como ser social, transita por diferentes contextos e grupos, seja na escola, na família, no trabalho, possibilitando a troca de experiências com esses grupos e, a partir delas se identificando ou não com os mesmos e, desenvolvendo, quando há esta identificação, o sentimento de pertencimento (ANDRÉ, 2008). 
Na Geografia o termo identidade é compreendido, como sendo de caráter individual ou coletivo, ultrapassando a associação a características como sexo e origem étnica, mas dizendo respeito também ao espaço cultural e geográfico que o grupo habita (FONT; RUFÍ, 2006).

André (2008) salienta ainda a relevância do outro na construção da identidade, pois a partir do momento que o sujeito está inserido em determinado grupo e cultura, socializando com seus pares, ele vivencia diferentes trocas, tanto de cunho emocional quanto intelectual, motor, etc. Tais vivências acabam por moldá-lo enquanto ser social e, consequentemente seu processo identitário, visto que, é a partir dessas interações que os sujeitos são identificados e reconhecidos na sociedade (ANDRÉ, 2008).

Nessa perspectiva, todo grupo necessita de uma base material ou simbólica, que é o território, para nele construir sua identidade, conforme apresentado a seguir:

\footnotetext{
Mais uma vez: o que "define" o território é, em primeiríssimo lugar, o poder. Ou, em outras palavras, o que determina o "perfil" do conceito é a dimensão política das relações sociais [...]. Isso não quer dizer, [...] que a cultura (o simbolismo, as teias de significados, as identidades...) ou a economia (o trabalho, os processos de produção e circulação de bens) não sejam relevantes ou não estejam contemplados [...]. (SOUZA, 2013, p.88).
}

Esses espaços de referências vivenciados pelos grupos como suporte para sua construção identitária, em alguns casos recebem tamanha importância que acabam sendo sacralizados, propiciando o fortalecimento de uma identidade coletiva, que é acima de tudo territorial (HAESBAERT, 2006).

É relevante salientar que as identidades são mutáveis, estando em constante processo de construção e reconstrução, variando de acordo com as circunstâncias (FONT; RUFÍ, 2006). Logo, em função dessas multiplicidades e variações na escala espaço-tempo, as identidades são suscetíveis a tensões e contradições (FONT; RUFÍ, 2006), realidade essa já destacada quando se trata das comunidades quilombolas.

Em suma, mediante toda esta discussão pode-se afirmar que o território é uma das bases principais na fundamentação da concepção de identidade. E, o papel dessa identidade que tem referência no espaço, é imprescindível para a compreensão da realidade quilombola, uma vez que nestas comunidades, esta categoria, que se torna espacial, destaca-se.

Segundo Haesbaert (1999), estas identidades construídas a partir do território, tanto simbólico, quanto concreto deverão ser compreendidas como identidades territoriais, a exemplo das identidades das comunidades quilombolas. Nessa mesma perspectiva, Medeiros (2009, p.217) destaca que, "O território é um espaço de identidade ou pode se dizer que é um espaço de identificação". 
Tais identidades fortalecidas pelos territórios manifestam-se das mais diversas formas, podendo configurar-se em identidades locais, regionais ou nacionais (HAESBAERT, 2006).

Para Haesbaert (1999), uma das características principais da identidade territorial, é que recorre à dimensão histórica, do imaginário das pessoas, tendo como referência o território. Tal realidade é perceptível nas comunidades quilombolas, posto que as memórias coletivas e o imaginário popular dos grupos estão atreladas diretamente ao território. Portanto, pode-se afirmar que a memória também é um elo importante na apropriação e manutenção de um grupo de determinado território e na sua construção identitária.

Neste sentido, Pollak (1992, p. 204) destaca que:

Podemos portando dizer que a memória é um elemento constituinte do sentimento de identidade, tanto individual como coletiva, na medida em que ela é também um fator extremamente importante do sentimento de continuidade e de coerência de uma pessoa ou de um grupo em sua reconstrução de si.

De acordo com Haesbaert (1999), atualmente há um processo de resgate da identidade, devido a uma crise de valores, vivenciada no mundo atual. Tal fato se realiza por um processo de resistência a homogeneização da cultura e exclusão das minorias, provocado pelo capitalismo e pelo processo de globalização (HAESBAERT, 1999).

Haesbaert (1999) coloca ainda que para variados autores, a sociedade atual vivencia, em função da fluidez das relações, um desapego da base concreta do território, nos chamados processos de desterritorialização. Entretanto, vale salientar que mesmo nesses casos, nos quais a dimensão simbólica se sobrepõe ao concreto do território, os grupos sociais podem ainda criar uma identidade territorial (HAESBAERT, 1999).

Todavia, segundo Haesbaert (1999), essas identidades de forma geral, nos tempos de globalização, acabam por sofrer transformações, podendo apresentar-se como:

- identidades globais, marcadas pelos aspectos da globalização, e homogeneização cultural (HAESBAERT, 1999). Isto é, identidades que em função da globalização, perderam suas características particulares e, passaram a ser muito similares a outras, refletindo no comportamento dos sujeitos, nos produtos e serviços que utilizam, nos seus hábitos alimentares, entre outros aspectos.

- identidades pluriculturais, uma fusão do global/universal e local/particular (HAESBAERT,1999). São as identidades que tem interferência do global, sem perder sua essência particular.

- identidades de resistência, são aquelas marcadas por um profundo reforço de antigas memórias da coletividade (HAESBAERT, 1999). São as identidades que resistem ao processo de homogeneização fruto da globalização, mantendo-se tal qual foi concebida ou muito próxima a isso. 
Nessa perspectiva, a identidades das comunidades quilombolas, devem ser entendidas como identidades de resistências (HAESBAERT, 1999), posto que habitantes costumam conservar a memória vivida nessa base material, por meio de relatos orais, mitos, rezas entre outros (ITCG, 2008). E, também, identidades pluriculturais (HAESBAERT, 1999), em função de modificações ocorridas atualmente nessas comunidades e, de sua inserção, por exemplo, no uso de tecnologias, acompanhando a dinâmica mundial.

Portanto, pode-se afirmar que os conceitos de território, territorialidade e identidade territorial, se aplicam na dinâmica territorial destas comunidades. E que esta dinâmica passou por transformações a partir da criação das legislações quilombolas, os quais serão discutidas a seguir.

\section{CONFIGURAÇÃO IDENTITÁRIA E TERRITORIAL DAS COMUNIDADES QUILOMBOLAS APÓS LEGISLAÇÃO FEDERAL.}

As comunidades quilombolas, com a Constituição Federal de 1988 junto as lutas do Movimento Negro, passaram a ser objetivo de estudo e legislação. Diante desse novo panorama, começaram a ter um embasamento legal representado pelas legislações, em sua luta por reconhecimento e regularização fundiária. Tal conjuntura proporcionou ainda o surgimento de um novo sujeito, do ponto de vista legal, isto é, o quilombola (SILVA, 2013), visto que até então muitos remanescentes, desconheciam o termo e o que este implicava. Contudo, já manifestassem características intrínsecas as comunidades quilombolas.

O termo quilombo é utilizado no continente americano desde o início do processo de escravidão no século XVI (FIABANI, 2005). A nomenclatura era usada para designar as comunidades formadas por africanos escravizados que haviam deixado o regime de escravidão (FIABANI, 2005).

A palavra quilombo possui vários significados. Um deles é que teria se originado da língua quimbundo e significaria arraial ou acampamento. (FIABANI, 2005). Assim denominados, pois os ex-escravos recriavam nesses espaços, um modo de vida semelhante ao que levavam no continente africano, anterior ao processo de migração forçada para o Brasil. (SILVA, 2013). Tal termo, utilizado inicialmente no Estado de Minas Gerais, difundiu-se a partir do século XVIII pelo território brasileiro, em função do seu uso em documentos oficiais (FIABANI, 2005).

Dessa forma, a nomenclatura foi apropriada pela sociedade e pelas legislações nacionais, sendo utilizada até os dias atuais, para tratar desses grupos. Entretanto, é importante salientar que o Estado, incorporou a palavra quilombo, o termo remanescentes, quando trata-se das comunidades quilombolas atuais. De modo que, “[...] o emprego do termo implica a expectativa de encontrar, nas comunidades atuais, formas atualizadas dos antigos quilombos [...]” (ARRUTI, 2006, p.81). 
Todavia, em função do contexto de invisibilidade das populações afrodescendentes já relatado, os remanescentes quilombolas só foram reconhecidos a partir de movimentações que se iniciam na década de 1970, com as lutas do Movimento Negro e, que se materializam em 1988 com a Constituição Federal, que voltou o olhar para esses sujeitos, lhes fornecendo uma identidade e preocupando-se também com a questão da regularização fundiária das terras por eles ocupadas (SILVA, 2013).

Nesse sentido, o marco inicial nas legislações federais sobre esta questão é representando pelo artigo 68 do Ato das Disposições Constitucionais Transitórias (ADCT) da Constituição Federal de 1988, que iniciou no sentido legal a regularização fundiária das terras das comunidades quilombolas, estabelecendo ao Estado o papel de emitir os títulos para comprovação da posse destas terras. (BRASIL, 2012).

Entretanto, tenha sua importância, o ADCT 68 apresentava-se muito superficial e, não explicava o processo em sua totalidade. Isto é, não designava os critérios para as comunidades, serem consideradas como remanescentes quilombolas, ou ainda, qual órgão seria responsável pela regularização fundiária, entre outros aspectos.

Em função desse primeiro artigo pouco esclarecedor e dessa realidade confusa que na legislação brasileira apresentavam-se para com estas comunidades, inúmeras leis, portarias e decretos foram sendo criados, com o objetivo, de regulamentar a situação das terras, mas também estabelecer quem eram esses sujeitos quilombolas (SILVA, 2013).

Desse modo, foi criado em 29 de setembro de 2008 a Instrução Normativa $n^{\circ}$ 49, que considerou como remanescentes quilombolas, os grupos étnicos com trajetória histórica, que possuíssem relações territoriais próprias, de ancestralidade afro, relacionados ao processo de resistência e opressão sofrida historicamente (INCRA, 2008). E, as terras ocupadas por remanescentes de quilombos, aquelas que são utilizadas para sua reprodução (INCRA, 2008).

A fim de complementar a instrução anterior foi criada a Instrução Normativa $n^{\circ} 57$, em 20 de Outubro de 2009, que instituiu a obrigatoriedade de estudos técnicos e antropológicos como base para caracterização de uma comunidade como quilombola e, somente a partir desses estudos, é que seriam realizadas as delimitações de suas terras (INCRA, 2009).

Essas duas instruções normativas do INCRA, foram relevantes, pois definiram quem seriam esses sujeitos e quais as terras consideradas como território quilombola. Posto que, desde o ADCT $n^{\circ} 68$, o termo e a questão da terra passavam por vários impasses e confusões, estabelecendo a necessidade de estudos embasados cientificamente para a delimitação dessas terras, dificultando contestações por parte de outros interessados. 
Diante desse cenário é estabelecida uma parceria entre o Instituto Nacional de Colonização e Reforma Agrária - INCRA, responsável pela regularização das terras e a Fundação Cultural Palmares - FCP, responsável pela certificação das comunidades.

Tais dispositivos trouxeram a tona um debate até então esquecido e desconhecido por muitos, uma vez que “[...] refletem uma intensa discussão política entre alguns sujeitos, como poder público, comunidades quilombolas, Movimento Negro e demais interessados [...] como os fazendeiros" (SILVA, 2013, p. 60).

Nesse contexto, as legislações nacionais além de embasarem todo um histórico de lutas, pela permanência e usufruto das terras que historicamente pertenceria a estas comunidades, resultaram no surgimento de um novo sujeito, o quilombola (SILVA, 2013), que posteriormente teve sua identidade reforçada. Uma vez que, se fez necessário esta autoafirmação, pois um dos critérios do processo era a comunidade ser identificada e se autorreconhecer como quilombola.

Constata-se assim que tanto as lutas do Movimento Negro, quanto às legislações para identificação, reconhecimento e titulação das terras quilombolas, foram instrumentos imprescindíveis no processo de visibilidade destes grupos (LÖWEN SAHR; ALVES, 2011). Mediante todo esse contexto, foi possível o levantamento e titulação de várias comunidades em território brasileiro.

Essas alterações nas legislações federais nos últimos vinte anos deram as comunidades quilombolas visibilidade, além do que esse movimento jurídico também foi acompanhado por um movimento acadêmico, no qual as comunidades tornaram-se alvos de estudos, especialmente acerca de definições de uma comunidade quilombola na atualidade.

Entre os autores que passaram a investigar essas comunidades destaca-se Arruti (2006), que propõe que o conceito de Comunidades Remanescentes de Quilombos está pautado em três paradigmas, são eles: remanescentes, terras de uso comum e etnicidade.

O primeiro paradigma diz respeito às reminiscências relacionadas ao período escravista, isto é, aos requícios do passado, e que ainda podem ser observados nas comunidades quilombolas (ARRUTI, 2006). O segundo paradigma, refere-se à existência de um uso comunitário das terras e a posse e utilização dos recursos básicos do território, por meio de um conjunto de códigos e normas, que estabelecem uma territorialidade em comum (ARRUTI, 2006). E o terceiro paradigma, relaciona-se a etnicidade, na qual os quilombolas são entendidos como grupos étnicos, com normas e critérios próprios, que os diferenciam de outros grupos (ARRUTI, 2006).

Diante desse contexto, pautado nessa reconstrução semântica, política e histórica do termo quilombo e, na visibilidade proporcionada pelas legislações nacionais, discutidas anteriormente, atualmente tem-se no Brasil 2.474 comunidades certificadas como quilombolas (FCP, 2015), que se 
distribuem por quase todo território brasileiro, com predominância na região Nordeste, na sequência na região Norte, e em terceiro lugar na região Sudeste (ANJOS, 2004), conforme a figura 1 a seguir:
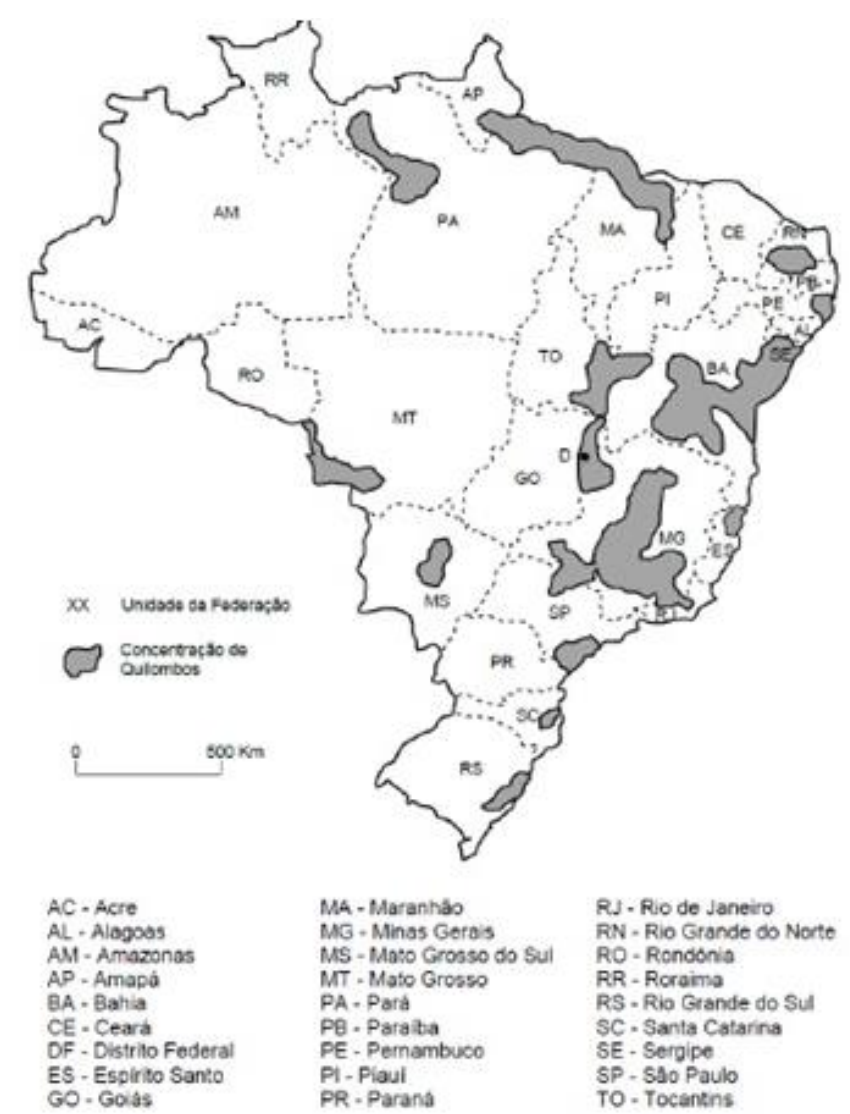
R.J - Rio de Janeiro
RN - Rio Grande do Nerte
RO - Rondonis
RR - Rcraims
RS - Rio Grande do Su
SC. Santa Catarina
SE- Sergipe
SP - SA0 Paulo
TO- Tocantns

Fonte: Adaptado de Anios (2000)

Desenho: Lowen Sahr (2012)

Figura 1 - Principais áreas de concentração de quilombos no Brasil - 2012

Fonte: Rafael Sanzio Araújo dos Anjos, 2009

Org.: Cicilian Luiza Löwen Sahr, 2012.

Vale destacar, que em alguns estados como é caso do Paraná, esta realidade de reconhecimento das comunidades quilombolas, só foi possível tardiamente, resultado de um panorama geral de invisibilidade dos afrodescendentes, em função da imagem que se veiculava, de um Estado predominantemente branco e de origem europeia (ITCG, 2008), resultado do Movimento Paranista, ocorrido nos anos 1920-1930 que tinha como objetivo, construir uma identidade para o Estado do Paraná (ITCG, 2008).

Esta identidade paranaense que se objetivava formar estava impregnada de ideias de progresso e desenvolvimento social (PETERS, 2005). Para esse propósito, utilizavam-se da construção de discursos e símbolos baseados na cultura europeia e nas contribuições indígenas (PETERS, 2005), resultando em um pacto de silêncio, e acentuando o já relatado legado de exclusão. 
Enfim, as legislações nacionais mesmo que tardiamente para alguns estados, como é o caso do Paraná, levou ao reconhecimento das comunidades quilombolas, alterando sua dinâmica territorial positivamente, pelo incentivo e valorização de sua territorialidade, principalmente em um primeiro momento, de grande expectativa com as políticas públicas quilombolas, ou negativamente pelos embates propiciados por este reconhecimento, pela posse da terra.

\section{CONSIDERAÇÕES FINAIS}

Até a Constituição Federal de 1988, não havia no cenário nacional, nenhuma discussão a respeito das Comunidades Remanescentes de Quilombos.

Entretanto, os dispositivos legais, criados a partir de 1988, junto as lutas do Movimento Negro, trouxeram a tona novamente os sujeitos quilombolas e, foram importantes, sobretudo, em um primeiro momento para criar politicamente uma identidade para essas comunidades. E, posteriormente para reforçar a identidade quilombola e sua territorialidade.

Tendo em vista que, se apropriar dessa identidade garantia a estas comunidades a certificação como remanescente quilombola, o acesso a políticas públicas e, principalmente a regularização fundiária. Elementos relevantes para estas comunidades, em função do que o território que habitavam representava em termos econômicos, políticos, culturais, históricos e sociais.

Nesta perspectiva, pode-se afirmar a relevância e aplicação dos conceitos de território, e territorialidades a esta realidade, dado o território ser a principal referência destas comunidades e sua identidade ser expressa a partir dele, configurando se em uma identidade territorial.

Entretanto, esta apropriação do termo quilombola e o seu uso atrelado ao processo de regularização fundiária, envolveu as várias comunidades nacionais em inúmeros embates, posto que significava a desapropriação daqueles que habitavam o território que, por direito legal seria dessas comunidades. Portanto, estas legislações alteraram diretamente a dimensão territorial e identitária dessas comunidades.

\section{REFERÊNCIAS}

ANDRÉ, M. C. O ser negro: a construção de subjetividades em afro-brasileiros. 1 ed. Brasília: LGE Editora, 2008. 266p.

ANJOS, R. S. A. Cartografia e cultura: territórios dos remanescentes de quilombos no Brasil. In: CONGRESSO LUSO-AFRO-BRASILEIRO DE CIÊNCIAS SOCIAIS, 8, 2004, Coimbra. Anais Congresso Luso-Brasileiro de Ciências Sociais. Coimbra: CES, 2004. p.1-16. 
ARRUTI, J. M. Mocambo: antropologia e História do processo de formação quilombola. 1. ed. Bauru: Edusc, 2006. 368 p.

COSTA, W. M. A Geografia Política Clássica. In: .Geografia Política e Geopolítica: discursos sobre o Território e Poder. São Paulo: Editora da Universidade de São Paulo, 1992. cap. 2, p.29-53.

FCP. Quadro Geral de Comunidades Remanescentes de Quilombos (CRQs), 2015. Disponível em: $\quad$ http://www.palmares.gov.br/wp-content/uploads/crqs/quadro-geral-por-estado-ate-23-022015.pdf. Acesso em: 20 de out. 2015

FIABANI, A. Mato, Palhoça e Pilão: o quilombo, da escravidão às comunidades remanescentes (1532 -2004). 1. ed. São Paulo: Expressão Popular, 2005. 424p.

FONT, J. N.; RUFÍ, J. V. Geopolítica, identidade, globalização. 1. ed. São Paulo: Annablume, 2006. 282p.

HAESBAERT, R. Identidades Territoriais. In: ROSENDAHL, Z.; CORRÊA, R. L. Manifestações da Cultura no Espaço. Rio de Janeiro: EDUERJ, 1999. cap.7, p. 169-190.

HAESBAERT, R. O mito da desterritorialização: do "fim dos territórios" à multiterritorialidade. 1.ed. Rio de Janeiro: Bertrand Brasil, 2004. 400p.

HAESBAERT, R. Território, Poesia e Identidade. In: HAESBAERT, R. Territórios alternativos. São Paulo: Contexto, 2006. cap.8, p. 143-158.

ITCG. Terra e cidadania: terras e territórios quilombolas. 1. ed. Curitiba: ITCG, 2008. 221p.

INCRA. Instrução Normativa $\mathbf{n}^{\mathbf{0}}$ 49, de 29 de setembro de 2008. Disponível em: http://www.incra.gov.br/portal/index.php?option=com_docman\&task=cat_view\&gid=297\&Itemid= 136\&limitstart=7>. Acesso em: 05 abr. de 2015.

INCRA. Instrução Normativa $\mathbf{n}^{\circ} \mathbf{5 7}$, de 20 de outubro de 2009. Disponível em: http://www.incra.gov.br/institucionall/legislacao--/atos-internos/instrucoes/file/243-instrucaonormativa-n-57-20102009. Acesso em: 10 abr. 2015.

LÖWEN SAHR, C. L.; ALVES, T. T. A despedida do adobe e sapê: passos e descompassos na política educacional. In: FRAGA, N. C. Territórios e fronteiras: (Re) arranjos e perspectivas, Florianópolis: Insular, 2011. cap.18, p. 383-398.

MEDEIROS, R. M. V. Território, espaço de identidade. In: SAQUET, M. A.; SPOSITO, E. S. Territórios e Territorialidades: teorias, processos e conflitos. São Paulo: Expressão Popular, 2009. cap. 10, p. 217-227. 
PETERS, A. P. O movimento paranista. In: SCORTEGAGNA, A.; REZENDE, C. J.; TRICHES, R. Paraná Espaço e Memória: diversos olhares histórico-geográficos. Curitiba: Bagozzi, 2005. cap.11, p. 256-281.

POLLAK, M. Memória e identidade social. Estudos Históricos, Rio de Janeiro, vol.5, n.10, p. 200$212,1992$.

RAFFESTIN, C. Por uma Geografia do Poder. Ed. Tradução: Maria Cecília França. São Paulo: Ática, 1993. 266p.

SANTOS, M; SILVEIRA, M. L. A questão: o uso do território. In: SANTOS, M; SILVEIRA, M. L.O Brasil: Território e Sociedade no início do século XXI. 9. ed. Rio de Janeiro: Record, 2006. cap. 1. p. 19-22.

SAQUET, M. A. Por uma abordagem Territorial. In: SAQUET, M. A.; SPOSITO, E. S. (Org's.). Territórios e Territorialidades: teorias, Processos e Conflitos. São Paulo: Expressão Popular, 2009. cap.4, p.73-93.

SILVA, C. H. Quilombolas paranaenses contemporâneos: uma identidade territorial agenciada? Uma análise a partir do exemplo de Adrianópolis no Vale do Ribeira Paranaense. 2013. 267 f. Tese (Doutorado em Geografia) - Universidade Federal do Paraná - UFPR, Curitiba, 2013.

SOUZA, M. L. Território e (des) territorialização. In: SOUZA, M. L. Os conceitos fundamentais da pesquisa sócio-espacial. 1. ed. Rio de Janeiro: Bertrand Brasil, 2013. cap. 4, p. 77-110.

Trabalho enviado em 04/11/2016

Trabalho aceito em 17/01/2017 